\title{
Evaluation of Efficacy of Intra-Articular Corticosteroid in Treatment of Early Stages of Adhesive Capsulitis of Shoulder Joint
}

\author{
Singh $\mathrm{AK}^{1 *}$, Narsaria $\mathbf{N}^{2}$ and Gupta $\mathrm{RK}^{3}$ \\ ${ }^{1}$ Department of Orthopedics, Government Medical \\ College, Banda, India \\ ${ }^{2}$ Department of Orthopaedics, Mayo Institute of Medical \\ Sciences, Barabanki, India \\ *Corresponding author: Ashutosh Kumar Singh, \\ Department of Orthopedics, Government Medical \\ College, Banda, India
}

Received: April 26, 2017; Accepted: June 14, 2017; Published: June 21, 2017

\begin{abstract}
Background: This study was conducted to evaluate clinical outcomes of intra-articular injection of corticosteroid in patients with idiopathic adhesive capsulitis.

Material and Methods: In our study, 100 patients with idiopathic adhesive capsulitis were injected $5 \mathrm{ml}$ of $1 \%$ lidocaine and $80 \mathrm{mg}$ methylprednisolone acetate through posterior approach in glenohumeral joint. Range of motion (ROM) and pain (visual analogue scale) was assessed at pre-injection, postinjection, and at follow-up visits (2 and 12 week). Functional outcome was assessed using Constant score.
\end{abstract}

Results: Average time from onset of symptom to treatment was 6.2 months (range, 2-11 months). VAS pain score got improved at 2 week follow up visit and 12 week follow-up visit. Constant score also improved at 2 week and 12 week follows up visit. Forward flexion and external rotation increased at 2 week and 12 week follow-up. 23 patients did not meet the criteria for recovery, and of those, 8 patients underwent arthroscopic capsular release due to non resolution of symptoms after average time of 20 weeks after injection.

Conclusion: Patients treated with intra-articular corticosteroid for idiopathic adhesive capsulitis showed significant improvement in clinical outcomes and range of motion.

Keywords: Capsulitis; Corticosteroid

\section{Introduction}

The treatment for idiopathic adhesive capsulitis of the shoulder is controversial. Treatment options include supervised physical rehabilitation, nonsteroidal anti-inflammatory medications oral corticosteroid intra-articular corticosteroid injection closed manipulation and surgical release (open or arthroscopic capsular release) [1-5]. Corticosteroid injection is one of the most commonly used treatments for adhesive capsulitis. It reduce synovial inflammation to decrease capsular fibrosis and allow improvement of motion with pain alleviation but it is also associated with complications like fat atrophy, skin pigment changes, septic arthritis, post-injection symptom flare/synovitis, facial flushing, anaphylaxis and steroid arthropathy [6,7].

The goal of this study was to evaluate outcomes and complications of intra-articular injection corticosteroid in patients with idiopathic adhesive capsulitis.

\section{Material and Methods}

100 patients with idiopathic adhesive capsulitis (stage 1 and stage 2) were included in our study from june 2014 to may 2016. Inclusion criteria were insidious onset of shoulder pain with limitation of both active and passive range of motion (forward flexion $<100^{\circ}$, external rotation at the side of $0^{\circ}-20^{\circ}$, and internal rotation below the thoracic vertebral level) [8] excluding other causes of pain with loss of motion at shoulder (Rotator cuff tendinopathy, Glenohumeral osteoarthritis, trauma). All these cases were diagnosed as a case of adhesive capsulitis shoulder based on history, clinical examination and radiographic evaluation (anteroposterior and axillary views). Institutional review board approval was granted and informed consent was obtained for all patients.

The glenohumeral joint was injected via a posterior approach. The solution injected contained $5 \mathrm{ml}$ of $1 \%$ lidocaine and $80 \mathrm{mg}$ methylprednisolone acetate (Depo-Medrol 2 ml; Pfizer). All patients received only one injection. All the cases were allowed to do simple pendulum exercises and reexamined after 15 minutes of injection to evaluate pain, range of motion at shoulder and stage of adhesive capsulitis. Oral anti-inflammatory medications and stretching exercises at home were continued.

ROM and pain (visual analogue scale) was assessed at preinjection, postinjection, and at follow-up visits. Functional outcome was assessed using Constant score [9] which consists of pain (15 points), activities of daily living (20 points), active and painless range of motion (40 points), and strength (25 points). All the patients who had regained motion to within $15^{\circ}$ of the contralateral side in both forward flexion and external rotation as well as internal rotation on contralateral side were considered recovered. 


\section{Results}

The average age was 52.8 years (range; 24 to 84 ). 72 patients were female and 28 were male. The right shoulder was involved in 60 patients (60\%), and the dominant side was involved in 65 patients (65\%). Average follow-up period was 12 weeks (range; 8- 24 weeks). Average time from onset of symptom to treatment was 6.2 months (range, 2-11 months). Nine patients were lost to follow up in this study. Assessment of 93 patients was done in this study.

At preinjection time, VAS pain score was $7.6( \pm 2.6)$ which got improved to $4.2( \pm 1.6)$ at 2 week follow up visit and to $3.2( \pm 1.8)$ at 12 week follow-up visit. Constant score improved from $29.5( \pm 14.8)$ at preinjection time to $44.8( \pm 12.9)$ at 2 week follow up visit and 56.8 $( \pm 16.2)$ at 12 week follow up visit. Forward flexion increased from $92.4( \pm 8.2)$ to $110.2( \pm 15.8$.) at 2 week follow up visit and $124.8( \pm 14.8)$ at 12 week follow-up. External rotation increased from $11.6( \pm 5.2)$ to $18.4( \pm 10.4)$ at 2 week follow up visit and $22.4( \pm 14.6)$ at 12 week follow-up. Internal rotation also increased from L3-L4 $(15.1 \pm 4.1)$ at baseline to T12-L1 $(12.9 \pm 3.6)$ at 2 week follow up visit $(\mathrm{P}=.006)$ and was maintained at T12-L1 $(12.4 \pm 4.2)$ at 12 week follow-up visit 23 patients did not meet the criteria for recovery, and of those, 8 patients underwent arthroscopic capsular release due to non resolution of symptoms after average time of 20 weeks after injection.

Six patients reported brief postinjection flare and two cases had local pruritus that resolved within short span of time.

\section{Discussion and Conclusion}

The primary goal of this study was to evaluate the efficacy of intraarticular corticosteroid injection in patients with idiopathic adhesive capsulitis. Various treatment options are reported in literature for patients with adhesive capsulitis with variable result [10-13]. The pathology involved in adhesive capsulitis is synovial hyperplasia and capsular fibroplasia with fibrosis and dense capsular scar formation $[14,15]$. Rodeo et al. reported role of cytokines and other inflammatory mediators in patients with adhesive capsulitis and Intra-articular corticosteroid decreases synovitis limits development of fibrosis $[16,17]$.

Hazleman 18 reported success of treatment with intra-articular corticosteroid to be dependent on the duration of symptoms. Van der Windt et al. compared intra-articular corticosteroid to 6 weeks of physical therapy for patients with painful stiff shoulders and re[ported significant improvements in pain, disability, and motion in the injection group [19]. Gam et al. [20] treated patients with adhesive capsulitis with either steroid injection or steroid injection and distension with $19 \mathrm{~cm}^{3}$ of Lidocaine. They found that the distension with steroid group (12 patients) used fewer analgesics and had improved motion compared to the steroid-only group (eight patients). Bulgen et al. [21] in their study treated patients to with steroid, physical therapy, ice, or supervised neglect. They reported that initial response in steroid group was most significant but no significant difference in final long-term outcome was reported when treatment groups were compared.

Many disadvantages of corticosteroid injection have been reported including periarticular calcification, cutaneous atrophy, cutaneous depigmentation, tendon rupture, avascular necrosis, and joint infection $[7,22]$ but in our study no significant adverse effect was reported. Weakness of this study was that there was no control group.

In conclusion, corticosteroid injection in the early stages of adhesive capsulitis leads to significant improvement in range of motion and pain.

\section{References}

1. Mao CY, Jaw WC, Cheng HC. Frozen shoulder: correlation between the response to physical therapy and follow-up shoulder arthrography. Arch Phys Med Rehabil. 1997; 78: 857-859.

2. Placzek JD, Roubal PJ, Freeman DC, Kulig K, Nasser S, Pagett BT. Longterm effectiveness of translational manipulation for adhesive capsulitis. Clin Orthop Relat Res. 1998; 356: 181-191.

3. Dacre JE, Beeney N, Scott DL. Injections and physiotherapy for the painfu stiff shoulder. Ann Rheum Dis. 1989; 48: 322-325.

4. Ogilvie-Harris DJ, Biggs DJ, Fitsialos DP, MacKay M. The resistant frozen shoulder. Manipulation versus arthroscopic release. Clin Orthop. 1995; 319: 238-248.

5. Pollock RG, Duralde XA, Flatow EL, Bigliani LU. The use of arthroscopy in the treatment of resistant frozen shoulder. Clin Orthop Relat Res. 1994; 304 : 30-36.

6. Wang CT, Lin J, Chang CJ, Lin YT, Hou SM. Therapeutic effects of hyaluronic acid on osteoarthritis of the knee: a meta-analysis of randomized controlled trials. J Bone Joint Surg Am. 2004; 86: 538-545.

7. Habib GS, Saliba W, Nashashibi M. Local effects of intra-articular corticosteroids. Clin Rheumatol. 2010; 29: 347-356.

8. Yoo JC, Ahn JH, Lee YS, Koh KH. Magnetic resonance arthrographic findings of presumed stage-2 adhesive capsulitis: focus on combined rotator cuff pathology. Orthopedics. 2009; 32: 22.

9. Othman A, Taylor G. Is the constant score reliable in assessing patients with frozen shoulder? 60 shoulders scored 3 years after manipulation under anaesthesia. Acta Orthop Scand. 2004; 75: 114-116.

10. Ogilvie-Harris DJ, Myerthall S. The diabetic frozen shoulder: arthroscopic release. Arthroscopy. 1997; 13: 1-8.

11. O'Kane JW, Jackins S, Sidles JA, Smith KL, Matsen FA III. Simple home program for frozen shoulder to improve patients' assessment of shoulder function and health status. J Am Board Fam Pract. 1999; 12: 270-277.

12. Zuckerman JD, Cuomo F. Frozen shoulder. In: Matsen FA, Fu FH, Hawkins RJ (eds) The shoulder: a balance of mobility and stability. American Academy of Orthopaedic Surgeons, Rosemont, 1993.

13. Hsu JE, Anakwenze OA, Warrender WJ, Abboud JA. Current review of adhesive capsulitis. J Shoulder Elbow Surg. 2011; 20: 502-514.

14. Alman B, Greel D, Ruby L, Al E. Regulation of growth and platelet-derived growth factor expression in palmar fibromatosis (Dupuytren's disease) by mechanical strain. Journal of Orthopaedic Research. 1996.

15. Border WA, Noble NA. Transforming growth factor beta in tissue fibrosis. $N$ Engl J Med 1994, 331: 1286-1292.

16. Rodeo SA, Hannafin JA, Tom J, Warren RF, Wickiewicz TL. Immunolocalization of cytokines and their receptors in adhesive capsulitis of the shoulder. J Orthop Res. 1997; 15: 427-436.

17. Bunker TD, Anthony PP. The pathology of frozen shoulder. A Dupuytren-like disease. J Bone Joint Surg Br. 1995; 77: 677-683.

18. Hazleman BL. The painful stiff shoulder. Rheumatol Phys Med. 1972; 11: 413-421.

19. van der Windt DAWM, Koes BW, Deville W, Boeke AJP, de Jong BA, Bouter LM. Effectiveness of corticosteroid injections versus physiotherapy for treatment of painful stiff shoulder in primary care. BMJ. 1998; 317: 1292 1296.

20. Gam AN, Schydlowsky P, Rossel I, Remvig L, Jensen EM. Treatment of 
"frozen shoulder" with distension and glucorticoid compared with glucorticoid alone, a randomized controlled trial. Scand J Rheumatol. 1998; 27: 425-430.

21. Bulgen DY, Binder Al, Hazleman BL, Dutton J, Roberts S. Frozen shoulder: prospective clinical study with an evaluation of three treatment regimens. Ann Rheum Dis. 1984; 43: 353-360.
22. Habib GS. Systemic effects of intra-articular corticosteroids. Clin Rheumatol. 2009; 28: 749-756.
Austin J Orthopade \& Rheumatol - Volume 4 Issue 2 - 2017

ISSN: 2472-369X | www.austinpublishing group.com

Singh et al. (C) All rights are reserved
Citation: Singh AK, Narsaria N and Gupta RK. Evaluation of Efficacy of Intra-Articular Corticosteroid in Treatment of Early Stages of Adhesive Capsulitis of Shoulder Joint. Austin J Orthopade \& Rheumatol. 2017; 4(2): 1054. 